УДК 343.13

DOI $10.17223 / 22253513 / 18 / 4$

\title{
В.К. Зникин
}

\section{УГОЛОВНЫЙ ПРОЦЕСС БЕЗ КРИМИНАЛИСТИКИ И ОРД: ПРОБЛЕМНАЯ СИТУАЦИЯ}

\begin{abstract}
В статье речь идет о проблеме выделения научных специальностей, таких как уголовный процесс, криминалистика и ОРД, и последствиях для их развития. Автор приходит к выводу о том, что криминалистика и ОРД нужны постольку, поскольку могут быть востребованы уголовным прочессом, вместе с тем отмечает, что без криминалистики, судебно-экспертной деятельности и оперативно-розыскной деятельности исследования в области уголовного процесса замрут или будут топтаться на месте.

Ключевые слова: уголовный прочесс, оперативно-розыскная деятельность, номенклатура специальностей.
\end{abstract}

В настоящее время мы становимся свидетелями практического развала правоохранительной системы и ее органов, безнаказанности за содеянное преступное деяние с иллюзорным воспоминанием о неотвратимости наказания.

Не решенными на сегодняшний день остаются такие основные методологические вопросы, как что такое уголовное судопроизводство и профессиональная сыскная деятельность; по каким общим законам они существуют и развиваются; что является источником движущих сил их развития; каковы роль и место человека в этом развитии; основная цель освоения законов сыска, формирования внутреннего убеждения судьи и неотвратимости наказания за содеянное в уголовном процессе.

От решения этих вопросов зависит также выбор стратегии и тактики развития профессионального сыска и уголовного судопроизводства. Излагаемая ниже концепция автора есть попытка подойти к решению этих проблем.

Некоторые из этих вопросов ставились и решались как мыслителями древности, так и русскими учеными, которые в своих философских работах ближе всех подошли к этим проблемам, а также другими практиками от сыска, правоведами и философами современности. По своей сути, их труды есть одно из практических решений основного вопроса: сможет ли человечество выстоять в борьбе с криминальными проявлениями, основанными на низменных пороках своих соплеменников, и до каких пор общество будет терпеть данный произвол насилия и разгула преступности?

В последнее время философская мысль значительно отстает от развития как прикладных, так и теоретических наук.

Ну, пожалуй, хватит общих слов, перейдем к рассуждениям по заявленной теме. Что появилось раньше - курица или яйцо? Этот вопрос сотни лет волновал философов, ученых и простых обывателей. 
Проблема курицы и яйца - логический парадокс использования понятий с нечетким объемом. Все попытки разобраться в том, что из этого первично, а что вторично, заводят в тупик. На первый взгляд, загадка является поистине неразрешимой: ведь любая курица появилась из яйца, которое, в свою очередь, было снесено другой курицей. Круг замкнулся, вопрос повис в воздухе.

А теперь вернемся к вопросу: что появилось раньше - профессиональная сыскная деятельность или уголовное судопроизводство? Наверное, все-таки первым был сыск, а затем суд! Эта норма вытекает из формальной логики. Прежде чем посадить кого-либо на скамью подсудимых, нужно определить, т.е. выявить и установить того, кто совершил преступление, затем отыскать и задержать его, а потом уже судить.

Значит ОРД, как государственная ветвь профессионального сыска, первична во временном плане, а уголовный процесс вторичен!? Но оперативнорозыскная деятельность используется только в интересах уголовной юстиции и нужна лишь в том случае, если будет востребована уголовным судопроизводством.

Соотношение оперативно-розыскной деятельности с уголовным процессом и их взаимосвязь. Каковы они в реальной действительности?

Фактические данные, добытые в результате осуществления оперативнорозыскной деятельности, могут быть использованы в уголовном процессе в качестве доказательств лишь после того, как они нашли подтверждение в ходе доказывания в установленном уголовно-процессуальном порядке.

Тем не менее между добыванием и собиранием, документированием и доказыванием и между оперативной и процессуальной информацией нет необходимого соответствия. Основная причина - отсутствие указанных выше категорий оперативно-розыскной деятельности в нормах уголовнопроцессуального закона. И еще одна - не всегда качественное оформление результатов оперативно-розыскной деятельности.

Поэтому следует поддержать ученых, а также практических работников, в том, что назрела настоятельная необходимость усовершенствования процедуры вхождения в уголовный процесс информации, полученной с помощью проведения оперативно-розыскных мероприятий. Именно усовершенствования, а не упрощения [1. С. 11-12; 2. С. 39].

При этом нам представляется, что в доказывании по уголовным делам законным формам получения информации в процессе оперативно-розыскной деятельности должна соответствовать необходимая адаптированная уголовно-процессуальная форма их использования, и это должно получить законодательное закрепление.

Концепция оперативно-розыскного обеспечения раскрытия и расследования преступлений представлена здесь как комплексная целостная теоретическая система, объединяющая совокупность положений общенаучного, научно-практического и законотворческого характера, позволяющих на основе реального соотношения и взаимосвязи оперативно-розыскной деятельности и уголовного процесса в вопросах доказывания стандартизировать процесс получения, преобразования и использования фактической оперативной информации в интересах уголовного судопроизводства. 
Но теперь об этом говорить и спорить достаточно сложно. Научная специальность 12.00 .09 разъединена. Уголовный процесс, криминалистика и оперативно-розыскная деятельность больше не сойдутся на одном уголовнопроцессуальном исследовательском плацдарме и будут вскользь упоминать друг друга, расходясь бортами, как солидные лайнеры в океане юридической науки.

В действительности что оставление науки уголовного процесса в гордом одиночестве произошло неожиданно. Во-первых, вялое обсуждение данного проекта было. Просто до конца не верилось, что такое произойдет. Вовторых, постоянная язвительная критика криминалистики и оперативнорозыскной деятельности на страницах электронных СМИ. Один неприлично самовлюбленный «Живой уголок dr. Aleksandroffa» чего стоит. Насмешливоснисходительные опусы из этого источника, конечно, не радуют, но серьезные люди на него не реагировали. Как говорится: «Собака лает, караван идет».

Но все-таки свершилось. Приказ Минобразования в феврале 2012 г. поставил жирную точку. В Номенклатуру специальностей научных работников по юридическим наукам внесено изменение: специальность 12.00.09 назвать «Уголовный процесс», а криминалистику, судебно-экспертную деятельность и оперативно-розыскную деятельность объединить в рамках новой специальности - 12.00.12. Прозвучало четко и бескомпромиссно: «Отлучить, нельзя оставить!»

Номенклатуру утвердили, а паспортов указанных научных специальностей до сих пор нет! Значит, фактически утвердили то, чего еще нет. Попахивает волюнтаризмом. Это мы уже проходили.

История становления и развития научной специальности 12.00.09 за последние полтора десятка лет выглядит следующим образом:

- уголовный процесс и криминалистика;

- уголовный процесс; криминалистика; теория оперативно-розыскной деятельности;

- уголовный процесс, криминалистика и судебная экспертиза; оперативно-розыскная деятельность;

- уголовный процесс, криминалистика; оперативно-розыскная деятельность;

- уголовный процесс!

Чаще в этот период реформировались только органы государственной безопасности РФ.

Деятельность, называемая сейчас оперативно-розыскной, объективна и существует, по своей сути, вне зависимости от нашего сознания, а тем более желания или воли государства и общества, так как появилась гораздо раньше этих образований. Она входит в число «древнейших» сфер деятельности, поскольку ее результатом являются конкретные сведения о чем-либо или информация. Алгоритм такой деятельности логичен и конкретен - получение упреждающей информации для принятия оптимального управленческого решения. Эта деятельность есть средство обеспечения безопасности человека, общества, государства. Нахождение в безопасности - это нахождение в контролируемых условиях. Ведь не зря говорится: «Предупрежден, значит, воо- 
ружен!» Кто владеет информацией, тот владеет миром. Это очевидная аксиома, не требующая дополнительных доказательств.

Наука специфической тайной деятельности, или, как принято называть сейчас, оперативно-розыскной деятельности, стала привлекать внимание серьезных современных исследователей сравнительно недавно по причине предыдущей закрытости. История этой деятельности полна еще загадок, небылиц, недомолвок и белых пятен. Попытка же отдельных авторов делать нравственные оценки, а также выискивать и представлять различия между благородной разведкой и низменным шпионажем, контрразведкой и политическим сыском, проникновением в преступную среду и уголовным сыском не вносит конкретности и ясности в существо вопроса.

При этом следует признать, что открытое появление в научной специальности 12.00.09 теории оперативно-розыскной деятельности, безусловно, обогатило как саму теорию ОРД, так и науку уголовного процесса. Но отлучение ОРД от уголовного процесса все же состоялось.

Уголовный процесс - это процесс оперирования доказательствами. Чем оперировать, коли таких не имеется?

Криминалистика и ОРД нужны постольку, поскольку могут быть востребованы уголовным процессом в лице государственных правоохранительных структур и судом. В противном случае они могут быть востребованы другим партнером по уголовно-процессуальной проблемной ситуации, желающим уйти от наказания. С наступлением товарно-денежных отношений и реальной конкуренции это теоретически возможно.

А как быть с вопросами безопасности участников уголовного судопроизводства, всех без исключения, в том числе судей? Ведь получение (собирание и добывание) упреждающей информации для принятия оптимального управленческого решения по сбережению участников уголовного судопроизводства может уйти из условий осуществления ОРД. Отказался же уголовный процесс от быстрого и полного раскрытия преступлений.

Есть мнение, что в современных условиях уже нельзя сказать, что связи уголовного процесса с науками, обеспечивающими судопроизводство, более тесные и важные, чем с другими вышеупомянутыми науками.

Позвольте не согласиться. Оперативно-розыскная деятельность присутствует только там, где совершаются преступления. Выявление, предупреждение, пресечение и раскрытие преступлений и причастных к этому лиц - главная задача оперативно-розыскной деятельности. Розыск осуществляется тоже в сфере уголовной юстиции. Добывание информации об угрозах безопасности также рассматривается через призму Уголовного кодекса. При чем здесь гражданский, арбитражный и административный процессы? Выдавать желаемое за действительное еще рано. Профессиональная сыскная деятельность в России представлена в форме государственной в лице ОРД и негосударственной в лице частной детективной деятельности. Последняя фактически бесправна и загнана под неусыпный контроль конкурента в лице МВД.

Что касается тесноты связей уголовного процесса с науками, обеспечивающими уголовное судопроизводство, можно отметить, что без криминалистики, судебно-экспертной деятельности и оперативно-розыскной деятельности уголовный процесс замрет или будет топтаться на месте. 
Неужто объединение уголовного процесса с криминалистикой и оперативно-розыскной деятельностью в рамках одной научной специальности постоянно порождало противоречия между ними, искусственно сдерживало развитие самого уголовного процесса, особенно в части новых механизмов процессуальной деятельности, направленных на обеспечение прав и свобод личности?

Плюс от разделения безусловно есть. Наконец-то исчезнет непонимание самими процессуалистами сущности ОРД и криминалистики как обеспечивающих уголовный процесс субстанций. Когда ОРД появилась в «девятке», только ленивый процессуалист не приветствовал ее появление и не отразил свою позицию в солидной статье. После этого они становились «классиками ОРД» и всякий раз следовало прислушиваться к их мнению. Обратное допускалось не всегда. В зоне уголовного процесса могли соперничать только процессуалисты. И хорошо, если научные специальности 12.00 .09 и 12.00 .12 не будут в одном диссертационном совете.

По мнению отдельных теоретиков от юриспруденции, новация оптимизации научной специальности 12.00 .12 заключается в объединении в рамках одной научной специальности родственных прикладных юридических наук, обеспечивающих судопроизводство.

Они полагают, что соединение в рамках одной научной специальности криминалистики, судебно-экспертной деятельности и оперативно-розыскной деятельности позволит осуществлять комплексные научные исследования и тем самым выработать качественно новые подходы к получению розыскной и доказательственной информации, повышению эффективности уголовного, гражданского и арбитражного процессов, производства об административных правонарушениях.

При таком аргументе получится наука ради науки и бесперспективная практическая значимость результатов диссертационных исследований. Что будут исследовать криминалисты, эксперты и ученые от ОРД, если сфера уголовного процесса будет практически от них удалена?

Подводя итог сказанному, можно рискнуть и сделать предположение относительно сложившейся проблемной ситуации вокруг научной специальности 12.00.09. Без паспорта специальности, конечно, воспроизвести подобное будет трудно.

Диагноз: полная несостоятельность достижения целей и решения задач уголовного судопроизводства (неотвратимость наказания заменена на безнаказанность).

Прогноз: общество и государство постоянно будут проигрывать все процессы без оперативно-розыскного и криминалистического обеспечения уголовного судопроизводства.

Развитие (вектор последующих действий): при таком восприятии реальной действительности отлучение криминалистики и оперативно-розыскной деятельности от уголовного процесса со временем должно поменять пунктуацию. Очень хочется надеяться, что так и будет.

«Отлучить нельзя, - оставить!» 


\section{Лumepamypa}

1. Зайцева С.А., Зейналова Л.М., Громов Н.А. и др. Оперативно-розыскная деятельность: совершенствование форм вхождения ее результатов в уголовный процесс: учеб.-практ. пособие. М.: Изд-ль Шумилова И.И., 2004. 118 с.

2. Зникин В.К. Результаты ОРД в уголовном процессе // Законность. 2005. № 4. С. 37-39.

Znikin Valery K. Tomsk State University (Tomsk, Russian Federation)

\section{CRIMINAL PROCEDURE WITHOUT CRIMINALISTICS AND OPERATIONAL SEARCH ACTIVITY: A PROBLEMATIC SITUATION}

Key words: criminal procedure, operational search activity, nomenclature of specialties.

Nowadays, the following basic methodological questions seem to be unsettled: what criminal procedure and professional operative search activity are; according to what main general laws they exist and develop, what moving force is the source of their development; according to what common factors the inner conviction of a judge and inevitability of punishment in criminal procedure are formed. The choice of the development strategy and tactics of both a professional search procedure and criminal proceedings depend on the solution of the above problems.

The Criminal Procedural Code of the Russian Federation stipulates that the data obtained in consequence of operational search activity can serve as evidence in criminal proceedings only after it was confirmed in the course of proving under the established procedure. Nevertheless, there is no conformity between acquisition and collection, documentation and proving, between operational and procedural information. The main reason is the lack of the above categories of operational search activity in the norms of criminal procedural law.

Thus, it is necessary to support both scientists and practitioners and emphasize that there is an urgent need to develop the procedure of introducing the information obtained in the course of operational search events into criminal proceedings. Proving in criminal cases ought to involve legal forms of obtaining the information in the course of operational search activity that should be in conformity with adapted criminal procedural form of their use and this must be entrenched in legislation.

Nowadays much attention is paid to the science of specific secret activity or operational search activity. It is necessary to admit that introduction of scientific specialty 12.00 .09 - the Theory of operational search has enriched both the theory itself and criminal procedure on the whole. At present, the scientific legal workers' Nomenclature needs to be changed: specialty 12.00 .09 is to be named "Criminal procedure" while criminalistics, judicial-expert and operational search activities are to be combined under a new specialty 12.00 .12 . This sounds clearly and uncompromisingly: "Separate, impossible to retain!"

However, we need both criminalistics and operational search activity as they are in demand by criminal procedure legally represented by state law enforcement bodies and courts. Our society and state will always lose all lawsuits in the absence of operational search and criminalistics support in criminal procedure. Thus, it seems impossible to separate criminalistics and operational search activity from criminal procedure. I hope that the above phrase should sound like: "Impossible to separate, retain!" 


\section{References}

1. Zaytseva, S.A., Zeynalova, L.M., Gromov, N.A. et al. (2004) Operativno-rozysknaya deyatel'nost': sovershenstvovanie form vkhozhdeniya ee rezul'tatov v ugolovnyy protsess [Operativesearch activity: improving the forms of its results used in the criminal process]. Moscow: I.I. Shumilov.

2. Znikin, V.K. (2005) Rezul'taty ORD v ugolovnom protsesse [The OSA results in a criminal trial]. Zakonnost'. 4. pp. 37-39. 